\title{
Involuntary movements during thermolesion predict a better outcome after microelectrode guided posteroventral pallidotomy
}

Marcelo Merello, Angel Cammarota, Osvaldo Betti, Maria Ines Nouzeilles, Daniel Cerquetti, Horacio Garcia, Ralph Pikielny, Ramón Leiguarda

\begin{abstract}
Eight of the first 15 patients with advanced Parkinson's disease who underwent microelectrode guided posteroventral pallidotomy developed transient abnormal involuntary movements during thermolesion, four of whom also did so during high frequency macrostimulation. Abnormal involuntary movements found before thermolesion were choreic, ballistic, or choreoathetoid in nature, usually persisted less than 60 minutes, and were contralateral to the site of thermolesion in six and bilateral in two of them. The appearance of abnormal involuntary movements during macrostimulation or thermolesion of the internal globus pallidus correlated with better surgical outcome as measured by UPDRS motor items and CAPIT timed test, so that they seem to be of prognostic value.
\end{abstract}

(F Neurol Neurosurg Psychiatry 1997;63:210-213)

Keywords: Parkinson's disease; pallidotomy; involuntary movements

In the past few years many reports have confirmed the efficacy of microelectrode guided posteroventral pallidotomy (PVP $)^{1-6}$ in the treatment of Parkinson's disease. Pallidotomy is not a new procedure. As early as the 1950s surgeons had reported the beneficial effect of lesioning the internal segment of the globus pallidus (Gpi). ${ }^{7-9}$ Lesions at that time were performed on the basis of coordinates calculated from a stereotactic atlas ${ }^{10-13}$ which neglected individual anatomical variations.

The development of recording techniques and the knowledge of the functional anatomy of the different basal ganglia and thalamic nuclei from experiments on primates ${ }^{14-17}$ have improved the localisation of the lesion within the Gpi, as an electrophysiological rather than an anatomical target, with optimisation of benefit and limitation of complications.

Here we present the results of our first 15 microelectrode guided patients with PVP at three month follow up, discriminating those who presented hemichorea or hemiballismus at the moment of thermolesion (PVP related abnormal involuntary movements or PVPAIMs) and those who failed to do so.

\section{Materials and methods}

PATIENTS

Fifteen patients attending the movement disorders clinic at our institute who fulfilled clinical criteria for idiopathic Parkinson's disease were included in our CAPIT/PPV ${ }^{18}$ programme and underwent PVP on the basis of (1) bradykinaesia and rigidity as cardinal features; (2) severe peak dose or biphasic dyskinaesiae; (3) pronounced asymmetry of symptoms and signs; (4) absence of significant changes in the activity of daily living (ADL) score during the on or off examination due to severe dyskinaesiae which interfered as much as or more than Parkinson's disease symptoms with usual chores; and (5) absence of dementia. Two out of the 15 patients were excluded from the analysis, one due to a cerebral haematoma at the lesion site that caused severe hemiparesis and the other because thermolesioning was not performed as electrophysiological recordings could not be obtained. Tables 1 and 2 show the clinical features.

CLINICAL EVALUATION AND FOLLOW UP

Patients were evaluated according to the CAPIT protocol by means of a serial levodopa test during a six month preoperative period. ${ }^{18}$ The motor section of the UPDRS, timed arm tests, walking time, dyskinaesiae score, activities of daily living (ADL), and Hoehn and Yahr score were recorded in practically defined off and again when on after a single dose levodopa challenge. Patients were evaluated 24 hours, seven days, one, and three months postoperatively. Evaluations were made on an open basis, but blind videotape examinations by a further investigator are planned for the one year follow up.

SURGICAL PROCEDURE

Guided by the Talairach stereotactic system, a microelectrode was introduced and basal ganglia activity was recorded. The number of recording tracks performed at each operation depends on (1) the ability to unequivocally identify putamen, GPe, and GPi; (2) presence of motor drive (enhanced phase response to proprioceptive stimuli in GPi neurons); (3) correct identification of internal capsule by microstimulation; and (4) correct identification of the optic tract by microstimulation and activity recording after visual stimulation. After carrying out all these steps, GPi macrostimulation at 50,150, and $300 \mathrm{~Hz}$ was performed and clinical results were evaluated by a tapping 
Table 1 Clinical features

\begin{tabular}{|c|c|c|c|c|c|c|c|c|}
\hline Sex & $\begin{array}{l}\text { Age } \\
(y)\end{array}$ & Dominance & Initial site & Initial symptoms & $\begin{array}{l}\text { More affected } \\
\text { side }\end{array}$ & $\begin{array}{l}\text { Disease } \\
\text { duration (y) }\end{array}$ & $\begin{array}{l}\text { Side of } \\
\text { pallidotomy }\end{array}$ & $P P V-R-A I M$ \\
\hline $\mathrm{F}$ & 69 & $\mathrm{R}$ & LUL & Rigor & $\mathrm{L}$ & 25 & $\mathrm{R}$ & Yes \\
\hline $\mathrm{F}$ & 64 & $\mathrm{R}$ & LUL & Tremor & $\mathrm{L}$ & 15 & $\mathrm{R}$ & Yes \\
\hline M & 41 & $\mathrm{R}$ & RLL & Tremor & $\mathrm{R}$ & 8 & $\mathrm{~L}$ & Yes \\
\hline $\mathrm{F}$ & 56 & $\mathrm{R}$ & LUL & Tremor & $\mathrm{L}$ & 16 & $\mathrm{R}$ & No \\
\hline $\mathrm{F}$ & 73 & $\mathrm{R}$ & LUL & Rigor & $\mathrm{L}$ & 12 & $\mathrm{R}$ & No \\
\hline M & 45 & $\mathrm{R}$ & Head & Tremor & $\mathrm{L}$ & 21 & $\mathrm{R}$ & Yes \\
\hline$M$ & 71 & $\mathrm{R}$ & LLL & Tremor & $\mathrm{L}$ & 20 & $\mathrm{R}$ & Yes \\
\hline $\mathrm{F}$ & 52 & $\mathrm{R}$ & LUL & Tremor & $\mathrm{R}$ & 12 & $\mathrm{~L}$ & Yes \\
\hline M & 63 & $\mathrm{R}$ & RUL & Tremor & $\mathrm{L}$ & 12 & $\mathrm{~L}$ & No \\
\hline$M$ & 67 & $\mathrm{R}$ & LUL & Tremor & $\mathrm{L}$ & 9 & $\mathrm{R}$ & No \\
\hline $\mathrm{F}$ & 61 & $\mathrm{R}$ & LLL & Bradykinaesia & $\mathrm{L}$ & 15 & $\mathrm{R}$ & No \\
\hline$M$ & 60 & $\mathrm{R}$ & LUL & Bradykinaesia & $\mathrm{L}$ & 21 & $\mathrm{R}$ & Yes \\
\hline$M$ & 40 & $\mathrm{~L}$ & RUL & Bradykinaesia & $\mathrm{R}$ & 6 & $\mathrm{~L}$ & Yes \\
\hline
\end{tabular}

LUL=left upper limb; RLL=right lower limb; LLL=left lower limb; RUL=right upper limb.

score using an ad hoc instrument and some of the UPDRS items. A single $75^{\circ} \mathrm{C}, 60$ second lesion was performed at the site determined by electrophysiological indices.

\section{Results}

Eight patients developed AIMs during the thermolesion although they had previously been off medication for at least 18 hours. Although less intense, AIMs also developed in four of them during $300 \mathrm{~Hz}$ macrostimulation. Four of the patients exhibited chorea, one ballistic movements, and three choreoathetoid movements. In six patients the movements were contralateral to the site of the thermolesion, whereas in two they were bilateral. In all patients AIMs were transient; in seven they lasted 30 (SD 20) minutes, whereas in one case movements persisted for up to 12 hours. Based on the presence or absence of these involuntary movements, the patients were split into two groups.

Table 3 shows the clinical features in both groups. There were no significant differences in age, disease duration, UPDRS part 3 score, Hoehn and Yahr score, or sex ratio between the two groups. Stereotactic lesions were located according to Talairach coordinates at 3.8 (SD 1.2) $\mathrm{mm}$ anterior to the mid-commissural line and 19.8 (SD $1 \mathrm{~mm}$ ) lateral in the group without PVP-AIM and 3.5 (SD 1.1) $\mathrm{mm}$ anterior to the mid-commissural line and 20 (SD 2) $\mathrm{mm}$ lateral in the group with PVP-AIM (NS).

Significant between group differences in UPDRS motor score (UPDRS part 3) were analysed with a three way multivariate analysis of variance (MANOVA) (group (with or without PVP-AIM) repeated measures: stage (onoff) $\times$ time (pre-PVP, three month post-PVP)) There was a significant group $\times$ stage $\times$ time interaction $(F(1,11)=7.1 ; \mathrm{P}<0.02)$. Changes in motor score after PVP were significant both in patients with $(\mathrm{P}<0.00003)$ and without $(\mathrm{P}<0.0001)$ PVP-AIMs. In both groups improvement occurred to a significantly higher degree in the off stage $(\mathrm{P}<0.05)$. Patients with PVP-AIMs have had a significantly better improvement after PVP in off $(\mathrm{P}<0.006)$ than those without PVP-AIMs. Table 2 gives means (SDs).

In agreement with Lang et $a l,{ }^{19}$ we did not analyse all timed test items of CAPIT, but restricted our assessments to finger and foot tapping tests and gait velocity. The results of these analyses were as follows: three way MANOVA (group:(with or without PVP-AIM) repeated measures: stage (on-off) $\times$ time (pre-PVP, post-PVP)) were performed to analyse finger tapping score. Despite a significant stage $(F(1,10)=4.9 ; \quad P<0.05)$ and time $(F(1,10)=6.7 ; \mathrm{P}<0.02)$ interaction there were no significant differences in group $\times$ stage, group $\times$ time, stage $\times$ time, or group $\times$ stage $\times$ time interactions (table 3); three way MANOVA (group:(with or without PVP-AIM) repeated measures: stage (on-off) $\times$ time (pre-PVP, post-PVP)) were performed to analyse foot tapping score. We found a significant stage $\quad(F(1.11)=8.3 ; \quad \mathrm{P}<0.01), \quad$ time $(F(1,11)=6.6 ; \mathrm{P}<0.02)$, and group $\times$ stage $(F(1,11)=4.9 ; \mathrm{P}<0.04)$ interaction. Patients with PVP-AIMs improved after PVP both in off $(P<0.05)$ and on $(P<0.05)$, but more so in off stage $(\mathrm{P}<0.05) \quad($ table 3$)$; three way MANOVA (group:(with or without PVPAIMs) repeated measures: stage (on-off) $\times$ time (pre-PVP, post-PVP)) were performed to analyse gait speed. Significant stage $(F(1,11)=16.8 ; \mathrm{P}<0.001)$, time $(F(1,11)=12.7$; $\mathrm{P}<0.004)$, differences and group $\times$ time $(F(1,11)=4.87 ; \mathrm{P}<0.05)$, and stage $\times$ time $(F(1,11)=4.81 ; \quad \mathrm{P}<0.05)$ interactions were found. Gait speed improved after PVP to a greater degree in the on stage in patients with PVP-AIMs $(\mathrm{P}<0.005)$ (table 3$)$; and two way MANOVA (group:(with or without PVPAIMs) repeated measures: time (pre-PVP, post-PVP)) were performed to analyse dyskinaesia score. There was a significant reduction in dyskinaesia scores after surgery $(F(1,11)=145 ; \mathrm{P}<0.0001)$, more pronounced in the group with PVP-AIMs $(F(1,11)=5.5$; $\mathrm{P}<0.03$ ) (table 4).

\section{Discussion}

Our findings clearly indicate that the presence of transient AIMs during GPi thermolesioning correlated with better surgical outcome. Furthermore, as AIMs also developed in some patients during high frequency macrostimulation, they may help to confirm that the lesion will be placed at the appropriate site. AIMs during thermolesioning of the posteroventral region of the GPi has been previously reported by Lozano et $a l^{4}$ and by Laitenen, ${ }^{21}$ but their appearance was not linked with prognosis.

These results raise two important questions. Why does GPi thermolesioning improve levo- 
Table 2 Results of UPDRS motor section

\begin{tabular}{llll}
\hline & PPV-AIM group & Non-PPV-AIM group & All patients \\
\hline Off pre & $\left.27.7(8.9)^{\star}\right)$ & $30.0(7.9)^{\star \star}$ & $28.6(8.3)$ \\
On pre & $12.6(9.5)$ & $20.0(10.8)$ & $15.7(10.4)$ \\
Off post & $14.0(8.6)^{\star \star \star \star}$ & $22.8(7.0)^{\star \star \star \star \star}$ & $17.3(8.9)$ \\
On post & $8.8(5.9)$ & $16.4(10.6)$ & $11.7(8.5)$ \\
\hline
\end{tabular}

${ }^{\star} \mathrm{P}<0.00003 ;{ }^{\star \star} \mathrm{P}<0.0001 ;{ }^{\star \star \star} \mathrm{P}<0.006$. Values are means $(\mathrm{SDs})$. pre $=$ pre-PPV; post $=$ post $-\mathrm{PPV}$.

Table 3 Results of timed tests

\begin{tabular}{lccc}
\hline & PPV-AIM group & Non-PPV-AIM group & All patients \\
\hline Tap off pre & $20.0(16.8)$ & $12.8(3.1)$ & $17.6(14.0)^{\star}$ \\
Tap on pre & $10.0(4.3)$ & $7.2(2.0)$ & $9.1(3.8)$ \\
Tap off post & $7.9(2.1)$ & $7.2(2.6)$ & $7.6(2.2)^{\star}$ \\
Tap on post & $7.3(2.3)$ & $5.9(1.3)$ & $6.8(2.1)$ \\
Foot tap off pre & $37.4(24.9)^{\star \star \star}$ & $25.6(20.7)$ & $32.9(23.3)^{\star \star}$ \\
Foot tap on pre & $21.2(24.0)^{\star \star \star \star}$ & $9.0(0.8)$ & $16.5(19.3)^{\star \star}$ \\
Foot tap off post & $13.7(11.1)^{\star \star \star}$ & $19.6(17.0)$ & $16.0(13.3)^{\star \star}$ \\
Foot tap on post & $9.3(6.8)^{\star \star \star \star}$ & $10.3(2.4)$ & $9.7(5.4)^{\star \star}$ \\
Gait off pre & $18.9(51.6)^{\star}$ & $19.7(45.6)$ & $18.6(49.3)$ \\
Gait on pre & $14.1(19.2)^{\star}$ & $21.1(36.9)$ & $18.6(26.0)$ \\
Gait off post & $18.4(23.6)$ & $25.0(32.8)$ & $20.7(27.1)$ \\
Gait on post & $7.9(12.1)^{\star}$ & $20.7(29.7)$ & $16.1(18.9)$ \\
\hline
\end{tabular}

${ }^{\star} \mathrm{P}<0.05 ;{ }^{\star \star} \mathrm{P}<0.004 ;^{\star \star \star} \mathrm{P}<0.05 ;{ }^{\star \star \star \star} \mathrm{P}<0.05$. Values are means $(\mathrm{SDs})$. pre $=$ pre-PPV; post $=$ postPPV.

Table 4 Results of dyskinesia score

\begin{tabular}{llll}
\hline & PPV-AIM group & Non-PPV-AIM group & All patients \\
\hline Dyskinesia preoperative & $3.0(0.6)^{\star}$ & $2.7(0.8)^{\star}$ & $2.9(0.7)$ \\
Dyskinesia postoperative & $0.2(0.4)^{\star \star \star}$ & $0.8(0.4)^{\star \star \star}$ & $0.4(0.5)$ \\
\hline
\end{tabular}

${ }^{\star} \mathrm{P}<0.0001 ;{ }^{\star \star} \mathrm{P}<0.03$. Values are means (SDs).

dopa related involuntary movements ${ }^{20}$ as well as rigidity and bradykinaesia, and why is surgical benefit greater in patients who exhibit AIMs during lesioning?

The effect of PVP on bradykinaesia and rigidity could be attributed to relieving excessive thalamic inhibition exerted by the GPi as a result of degeneration of the nigrostriatal tract. $^{22}$ The pathophysiological basis of dyskinaesiae is poorly understood, but they are probably related to an inhibition of the indirect output from the striatum to the GPi passing through the subthalamic nucleus (STN). ${ }^{23}$ The ability of PVP to reduce levodopa related AIMs has been attributed to interruption of glutamatergic projections from the subthalamic nucleus. ${ }^{24}{ }^{25}$ Therefore, a well placed lesion in the motor part of GPi both ameliorates dyskinaesiae and improves motor function, ${ }^{4}$ and this could indicate that firing patterns rather than overall firing rates determine specific motor manifestations. Thus a surgically induced decrease in GPi activity may achieve improvement in both dyskinaesiae and parkinsonian symptoms and signs, ${ }^{26}{ }^{27}$ wholly or partly by abolishing abnormally patterned activity. Limousin et $a l^{28}$ suggested that differences in time and voltage of STN stimulation exerted different effects on AIMs and bradykinaesia, suggesting that each effect is mediated by different mechanisms.

High frequency macrostimulation or lesion of the posteroventral region of the GPi may trigger transient AIMs through a direct sudden excitation of the cerebral cortex due to acute disinhibition of the VA/VL thalamic nuclei or indirectly through the centromedianstriatopallidothalamic loop. The centromedian thalamic nucleus receives projections from the pallidum and sends excitatory inputs (most likely glutamatergic) to the striatum that regulate the activity of the medium spiny projection neurons. Disinhibition of centromedian nucleus neurons may trigger a massive and transient dopamine release from nigrostriatal terminals thus causing the AIMs. ${ }^{169}$ The final effect could be mediated through the GPi/SNr output structures or through GPe inhibition of the reticular nucleus of the thalamus, as reticularis neurons normally exert an inhibitory activity on both pallidal and cerebellar areas of the motor thalamus. ${ }^{30}$

Whatever the physiopathological mechanism underlying the phenomenon, the appearance of AIMs during macrostimulation or thermolesion of the GPi seems to imply optimal lesion placement and to predict a better surgical outcome.

1 Sutton J, Couldwell W, Lew M, et al. Ventroposterior medial pallidotomy in patients with advanced Parkinson's disease. pallidotomy in patients with

2 Iacono R, Lonser R. Reversal of Parkinson's akinesia by pallidotomy. Lancet 1994;343:1095-6.

3 Iacono P, Shima F, Lonser R, Kuniyoshi S, Maeda G, Yamada $S$. The results, indications, and physiology of posteroventral pallidotomy for patients with Parkinson's disease. Neurosurg 1995;36:1118-25.

4 Lozano A, Lang A, Galvez-Jimenez N, et al. Effect of GPi pallidotomy on motor function in Parkinson's disease. Lancet 1995;346:1383-7.

5 Baron M, Turner R, Vitek J, Kandoke I, Bakay R, De Long $M$. Lesions of the internal segment of the globus pallidus (GPI) in Parkinsonian patients improve motor performance bilaterally [abstract]. Neurology 1994;44:702P.

6 Vitek J, Baron M, Kaneake I, Turner R, Bakay R, De Long $M$. Microelectrode guided pallidotomy is an effective treatment for medically intractable Parkinson's disease [abstract]. Neurology 1994;44:703P.

7 Narabayashi H, Okuma T. Procaine-oil blocking of the globus pallidus for the treatment of rigidity and tremor of parkinsonism. Proc fpn Acad 1953;29:134-7.

8 Svennilson E, Torvik A, Lowe R, et al. Treatment of Parkinson's by stereotactic thermolesions in the pallidal region. a clinical evaluation of 81 cases. Acta Psychiatr Neurol Scand 1960;35:358-77.

9 Laitinen L, Vilkki J. Measurement of parkinsonian hypokinesia with Purdue pegboard and motor reaction time test. In: Siegfried J, ed. Parkinson's disease. Berlin: Hans Huber, 1973;2:185-92.

10 Laitinen L. Brain targets in surgery for Parkinson's disease. f Neurosurg 1966;62:349-51.

11 Laitinen L, Johansson G, Sipponen P. Impedance and phase angle as a locating method in human stereotaxic surgery. $\mathcal{F}$ Neurosurg 1966;25:628-33.

12 Laitinen L, Bergenheim A, Hariz M. Leksell's posteroventral pallidotomy in the treatment of Parkinson's disease. $\mathcal{F}$ Neurosurg 1992;76:53-61.

13 Brierley JB, Beck E. The significance in human stereotactic brain surgery of individual variation in the diencephalon and globus pallidus. 7 Neurol Neurosurg Psychiatry 1959;22: $1-10$.

14 Alexander GE, Crutcher M. Functional architecture of basal ganglia circuits: neural substrates of parallel processing. Trends Neurosci 1990;13:266-71.

15 Alexander GE, Crutcher M, De Long MR. Basal ganglia thalamo cortical circuits: parallel substrates for motor, oculomotor prefrontal, and limbic functions. Prog Brain Res 1990;85:119-46.

16 Parent A, Hazrati L. Functional anatomy of the basal ganglia. I The cortico-basal ganglia-thalamo-cortical loop. Banglia. I The cortico-basal gan

17 Delong M. Primate models of movements disorders of basal ganglia origin. Trends Neurosci 1990;13:281-5.

18 Langston J, Widner I, Goetz C, et al. Core assessment program for intracerebral transplantation (CAPIT). Mov Disord 1992;7:2-13.

19 Lang AE, Benavid AL, Koller WC, et al. The Core assessment for intracerebral transplantation. Mov Disord 1995;10:527-9.

20 Marsden CD, Obeso JA. The functions of basal ganglia and the paradox of stereotaxic surgery in Parkinson's disease. Brain 1994;117:877-97.

21 Laitenen LV. Pallidotomy for Parkinson's disease. Neurosurg Clin N Am 1995;6:105-12.

22 Albin RL, Young AB, Penney JB. The functional anatomy of basal ganglia disorders. Trends Neurosci 1989;12:366-75.

23 Mitchel IJ, Boyce S, Sambrook MA, Crossman AR. A2-deoxyglucose study of the effects of dopamine agonists on the parkinsonian primate brain. Implications for the 
neural mechanism that mediate dopamine agonist-induced dyskinesias. Brain 1992;115:809-24.

24 Dogali M, Fazzini E, Kolodny E, et al. Stereotactic ventral pallidotomy for Parkinson's disease. Neurology 1995;45: 753-61.

25 Bergman H, Wichmann T, DeLong MR. Reversal of experimental Parkinsonism by lesions of subthalamic nucleus. Science 1990;249:1346-8.

26 Greenamyre JT. Pharmacological pallidotomy with glutamate antagonists? Ann Neurol 1996;39:557-8.

27 Papa SM, Chase TM. Levodopa induced dyskinesias improved by a glutamate antagonist in parkinsonian monkeys. Ann Neurol 1996;39:574-8.

28 Limousin P, Pollak P, Hoffman D, et al. Abnormal involuntary movements induced by subthalamic nucleus stimulation in parkinsonian patients. Mov Disord 1996;11:231-5.

29 Parent A, Hazrati L-N. Functional anatomy of the basal ganglia. II. The place of subthalamic nucleus and external pallidum in basal ganglia circuitry. Brain Res 1995;20:12854 .

30 Vitek JL, DeLong MR, Alexander GE. Physiologic properties and somatotopic organization of the primate motor thalamus. $\mathcal{F}$ Neurophysiol 1994;71:1498-513. 